AGATA HOŁOBUT

iD https://orcid.org/0000-0002-9445-9060

Uniwersytet Jagielloński

agata.holobut@uj.edu.pl

\title{
W SIECI KOMUNIKACJI MIEJSKIEJ: MIASTA W PRZEKŁADZIE. SKRZYŻOWANIA JĘZYKA I PAMIĘCI SHERRY SIMON
}

Sherry Simon 2020. Miasta w przekładzie. Skrzyżowania języka i pamięci, przeł. Justyna Arabska, Magdalena Brodacka, Melania Chotyńska, Magda Heydel, Ewelina Jurczenia, Karolina Koprowska, Agata Skrzypek, Martyna Szczepaniak i Sylwia Więcek, pod redakcją naukową Magdy Heydel, Kraków: Wydawnictwo Uniwersytetu Jagiellońskiego.

\section{Abstract \\ City Communication Network: Sherry Simon's Cities in Translation: Intersections of Language and Memory}

The article reviews Sherry Simon's seminal book Cities in Translation: Intersections of Language and Memory (Routledge, 2012) recently rendered into Polish. The Canadian scholar combines urban studies with comparative literature, translation, translator and memory studies to provide insight into linguistic and cultural interactions in the "dual cities" of Calcutta, Trieste, Barcelona and Montreal. An attempt has been made to present Simon's research against the backdrop of Translational Turn in the study of culture and the Cultural Turn in the study of translation.

Keywords: Sherry Simon, urban studies, postcolonial studies, self-translation, translation writing

Słowa kluczowe: Sherry Simon, studia miejskie, przekład postkolonialny, autotranslacja, pisarstwo przekładowe 
Odkąd przekładoznawcy unieśli wzrok sponad zadrukowanych kartek, żeby przyjrzeć się lepiej kulturowej rzeczywistości, mikroskopowe analizy tłumaczeń zaczęły ustępować miejsca teleskopowym ujęciom społeczno-ideowych okoliczności powstania tekstu, obrazom procesów dziejowych kształtujących komunikację międzykulturową oraz zbliżeniom na postaci, które w tej komunikacji uczestniczą. Odbiciem zwrotu kulturowego w przekładoznawstwie jest opisywany od ćwierćwiecza zwrot przekładowy w naukach humanistycznych i społecznych (por. Bassnett 1998, 2012; Heydel 2017; Bachmann-Medick 2016). Kategorie wykorzystywane w badaniach nad tłumaczeniem stają się kluczem do rozważań nad konfliktem i hierarchią władzy, różnicą kulturową i migracją, zagadnieniami pamięci kulturowej i tożsamości, wymianą idei oraz negocjacją znaczeń ponad podziałami. Pomagają „myśleć pomiędzy” czy też „myśleć pograniczem” (Bachmann-Medick 2013: 187) ${ }^{1}$.

Przekładoznawstwo rozumiane nie tyle jako dyscyplina, ile metodologia przydatna w różnych typach badań humanistycznych i społecznych (Heydel 2017; Bassnett 1998, 2012) ułatwia obserwację kultury, sztuki, społeczeństwa i języka przez pryzmat wzajemnych styków, zwarć i przepływów, a pisane z jej perspektywy prace wymykają się prostym klasyfikacjom i same stają się tworami granicznymi. Znakomitym przykładem takiego sposobu myślenia o świecie i/w tłumaczeniu jest monografia Sherry Simon Miasta w przekładzie. Skrzyżowania języka i pamięci (2020) która ukazała się niedawno w serii Translatio nakładem Wydawnictwa Uniwersytetu Jagiellońskiego, pod redakcją naukową Magdy Heydel. Książka dokumentuje ważny etap w twórczości kanadyjskiej badaczki, która na przełomie wieków przyczyniła się do uporządkowania i rozwoju feministycznych i postkolonialnych studiów nad tłumaczeniem jako autorka pionierskiej monografii Gender in Translation (1996) oraz współredaktorka tomu Changing the Terms: Translating in the Postcolonial Era (2000), a od niemal dwudziestu lat rozwija oryginalną refleksję nad wielojęzycznością w przestrzeni miejskiej, łącząc dorobek badań nad metropolią ze studiami nad literaturą, przekładem, tłumaczami i pamięcią. Publikacja wyznacza również ważny punkt na mapie rodzimego przekładoznawstwa: oto na polskie półki trafia kolejny tytuł szeroko komentowany w światowych kręgach akademickich.

Simon podjęła pierwszą refleksję nad wielogłosem miasta w swojej wczesnej monografii Translating Montreal: Episodes in the Life of a Divided

1 Przekłady cytatów z anglojęzycznych źródeł - A.H. 
City (2006), opisując „wrażenie życia pośród rywalizujących kodów” (2006: 218) i kreśląc sceny z udziałem pisarzy, dziennikarzy, awanturników, artystów - jak to sama ujęła - „wiedzionych na tłumaczenie” w kolonialnej metropolii (2006: 11). Tej tematyce poświęciła też swoją najnowszą książkę Translation Sites: A Field Guide (2019), w której tropi przekład w konkretnych - naznaczonych wielokulturowością - przestrzeniach: na ulicach Kairu i Montrealu, w sarajewskim hotelu, japońskim ogrodzie w Irlandii, praskiej operze czy lwowskiej synagodze. Jak pisze autorka, tłumaczenia udrażniają szlaki handlowe, umożliwiają przepływ informacji i pomagają ludziom współistnieć na jednej ulicy, ,jednak żeby zauważyć przekładowy charakter miast i obiektów, trzeba rozpoznać cienie dawnych czasów i języków" (2019: n.d.). Najlepszą lekcją tak rozumianej wrażliwości są właśnie Miasta w przektadzie, sytuujące się w samym centrum historyczno-topograficznych rozważań autorki (wersja angielska ukazała się w 2012 roku). Czego nas uczą i dlaczego warto je zwiedzić?

Simon skupia uwagę na miejscach będących siedzibą (co najmniej) dwóch „historycznie zakorzenionych wspólnot językowych”, połączonych wzajemnymi społecznymi i artystycznymi współzależnościami. Interesują ją zatem miasta, które są nie tyle „dwujęzyczne”, ile pozostają „w [ciągłym AH] przekładzie" (Simon 2020: 20). Autorka rozumie pod tym pojęciem szereg (między)kulturowych praktyk, takich jak wymiana poglądów między przedstawicielami różnych środowisk etnicznych i społecznych, pisarstwo przekładowe, transpozycja muzyki wschodu na zachodnie instrumentarium czy tłumaczenie siebie (autotranslacja) i innych (przekład właściwy). Rozpatruje te zjawiska na przykładach konkretnych twórców (pisarek i pisarzy, misjonarzy i skandalistów, tłumaczek i tłumaczy, artystów wizualnych czy architektów), którzy zamieszkują przestrzeń „pomiędzy” językowymi tożsamościami i punktami widzenia, tworząc $\mathrm{i}$ bytując w miastach podzielonych językowo przez historię i politykę, w miastach „dwoistych”, takich jak Nikozja, Sarajewo, Jerozolima, czy te, którym autorka poświęciła odrębne rozdziały w swojej książce: Kalkuta, Triest, Barcelona i Montreal. Jak wskazuje Simon, organizacja przestrzenna tych metropolii łączy się ściśle z wpisaną w nie pamięcią kulturową oraz choreografią społeczną (trajektoriami ludzi i prądów umysłowych). Mury oraz szyldy zmieniają się w palimpsesty i porastają warstwami wy- i przegryzających się wzajemnie języków, pasaże łączą dzielnice przynależne różnojęzycznym społecznościom, świątynie przechodzą z rąk do rąk, służąc kolejnym pokoleniom i wyznaniom. 
Simon czerpie inspirację z dorobku badaczy przekonanych, że „,przestrzeń miejska ma szczególną władzę nad wyobraźnią” (Simon 2020: 22). Sięga do rozwijających się od niedawna badań nad metropolią jako ośrodkiem procesów obywatelskich i ruchów demokratycznych. Zwraca jednak uwagę, że te socjologiczne, urbanistyczne, polityczno-geograficzne czy historyczne spojrzenia na miasto wyraźnie pomijają wątek jego naturalnej (a nieraz również ukonstytuowanej prawnie) wielojęzyczności, która staje się źródłem napięć i bodźcem do tworzenia więzi ponad podziałami. „Praktycznie nie istnieje systematyczna dyskusja o języku i jego interakcjach jako elementach tożsamości miast" - pisze we wstępie do książki (Simon 2020: 25).

Postanawia sama podjąć taką dyskusję, sięgając po narzędzia współczesnego przekładoznawstwa, zainteresowanego ukrytymi nierównościami kulturowymi, politycznymi i gospodarczymi. Szeroko rozumiane thumaczenie stanowi zdaniem badaczki „część sił działających w danym momencie historycznym” i „nie można automatycznie uznawać go za słowo przyjazne”. Wręcz przeciwnie: należy traktować przekłady jako „kulturowe artefakty, które ucieleśniają zarówno sytuacje rywalizacji i napięcia, jak i pragnienie utrzymania łączności” (Simon 2020: 26). Artefakty powstałe w konkretnych materialnych, politycznych historycznych okolicznościach, którym są podporządkowane i którym dają świadectwo. Zadaniem badacza jest rekonstrukcja tych okoliczności, dlatego Simon - jak sama to ujmuje - skłania się w swojej książce „ku narracjom objaśniającym powody tłumaczenia; ku historiom wyjaśniającym przyczyny, dla których przekracza się granice języków" (2020: 27).

Scenerii dla tych przekroczeń szuka w miastach naznaczonych „językow[a] niepewnośc[ią] i dwujęzyczn[a] estetyk[a]”. Jej zdaniem pomaga ona stworzyć model „nowego rodzaju obywatelstwa; takiego, które stawia opór, które nie chce niewymagającej i bezproblemowej komunikacji uznawać za normę" (Simon 2020: 18). Zainteresowane współistnieniem oraz współzawodnictwem języków (i niesionej przez nie pamięci kulturowej), które leży u podstaw tłumaczenia (siebie/sobie/innych/innym) jest więc u Simon postawą etyczną. Autorka pisze:

Aby zrozumieć, jak języki wchodzą w interakcje i dialogują ze sobą, koncentruję się na [...] obszarach negocjacji, przestrzeniach, gdzie dzięki przekładowi powstają połączenia. Mniej mnie interesuje, jak jednostki żonglują mnogimi kodami i wielojęzycznymi tożsamościami, bardziej interesują mnie tłumacze, 
którzy zapewniają transfer i cyrkulację idei. [...] Tłumacze [...] przenoszą idee z przestrzeni miasta na wspólną, publiczną arenę i inicjują nowe formy dialogu (Simon 2020: 18).

Zgodnie z tym założeniem Simon koncentruje się na postaciach, które poprzez swoją działalność (pisarstwo, aktywizm kulturowy, tłumaczenie właściwe) budują intelektualne, językowe i obyczajowe kładki oraz „pasaże”; troszczą się o wzajemną wymianę idei w miastach naznaczonych historycznie rozwarstwieniem językowymi i kulturowym. Jak wyjaśnia, opisywani przez nią tłumacze to „obywatele konkretnych miast, którzy działają dzięki specyficznym układom historycznym i językowym tych miejsc", a każde miasto „narzuca własne wzorce interakcji, które wyrastają z jego przestrzeni i narracyjnej przeszłości” (2020: 19); z kształtujących tę przestrzeń wzorców demograficznych, układów instytucjonalnych, tradycji estetycznych.

Simon skupia się na czterech szczególnych punktach w czasoprzestrzeni, którym poświęca kolejne rozdziały: (1) dziewiętnastowiecznej Kalkucie (1800-1880), w której wpływy kolonialne ścierają się z endemiczną tradycją bengalską; (2) habsburskim Trieście (1850-1918), w którym niemieckie wzorce intelektualne przyczyniają się do nietypowego rozwoju włoskojęzycznej twórczości; (3) współczesnej Barcelonie (1975-2000), w której ściera się i hybrydyzuje dziedzictwo kastylijskie i katalońskie, a wreszcie (4) na kanadyjskim Montrealu (1940-2000), w którym anglo- i frankofońskie strefy wpływów nie pozostały obojętne na bogate dziedzictwo kultury jidyszowej. Pozorny „dualizm” tych czterech przestrzeni geograficznych nie odwodzi Simon od refleksji nad rolą „trzecich przestrzeni”, zamieszkiwanych i kształtowanych przez przybyszów spoza tego na pierwszy rzut oka spolaryzowanego spektrum kulturowego (choćby Żydów w Montrealu czy migrantów z Afryki Północnej w Barcelonie). Simon kreśli szczegółowy obraz architektury, historii, politycznego i kulturowego dziedzictwa wspomnianych metropolii i w tak skonstruowanej scenografii ustawia postaci bohaterów swojej opowieści, czyli - jak sama ich nazywa - „tłumaczy”. Wyjaśnia, że wszyscy oni „włączają przekład w szersze projekty kulturowe, a ich działania często przekraczają definicję konwencjonalnego transferu językowego" (Simon 2020: 24), przyczyniając się do propagowania idei nowoczesności, rozumianej jako „świadomość pluralizmu kodów, jako myślenie dzięki tłumaczeniu i poprzez tłumaczenie, jako ciągłe testowanie granic ekspresji” (Simon 2020: 23). 
Wśród postaci, którym poświęca szczególnie dużo uwagi, znaleźli się między innymi: James Long, anglikański ksiądz zadurzony i zanurzony w kulturze bengalskiej, co znalazło wyraz w jego synkretycznych przekładach tekstów świętych, Bankim Chandra Chatterjee, niespełniony anglojęzyczny prozaik, a zarazem autor pierwszych powieści napisanych po bengalsku; dziewiętnastowieczna tłumaczka francuskiej poezji Toru Dutt; Italo Svevo z Triestu, który przełożył na język włoski niemiecką wrażliwość literacką; barcelońscy pisarze dokonujący autotranslacji (lub ostentacyjnie odmawiający przekładu); uwikłany w żydowskie, anglokanadyjskie oraz frankofońskie dziedzictwo literat i bard Leonard Cohen. Simon mówi o wzajemnych zależnościach pomiędzy społecznościami dwoistych miast w kategoriach oddalania (distancing), czyli wzmacniania grupowych odrębności, oraz rozszerzania (furthering), czyli budowania wspólnych, żywych, międzykulturowych wartości. W te procesy również uwikłany jest przekład, służąc uwypuklaniu obcości (choćby w obliczu zaniku języków z powodu represji) lub twórczemu obcowaniu i wymianie poglądów (Simon nazywa je przeciwdziałaniem brązowieniu).

Siła tej propozycji tkwi w połączeniu panoramicznego oglądu, potrzebnego do opisu wielkich przemian historycznych i mechanizmów kulturowych, z punktowym, lokalnym wglądem, który pozwala odsłonić czyjąś prawdę, stworzyć ciekawe studium przypadku. Tłumaczenie, jak pokazuje Simon, potrzebuje obu tych perspektyw badawczych. Autorka imponuje erudycją i pomysłowością. Jej nieszablonowe rozważania zainteresują nie tylko przekładoznawców, ale również badaczy literatury i kultury. Z pewnością nie jest to podręcznik, który uczy lektury tekstu (nie znajdziemy w nim żadnej jego analizy); to raczej przewodnik uczący odbioru miejskiej rzeczywistości i wyczulający na językowe oraz kulturowe palimpsesty. Spacer z Sherry Simon wymaga co prawda solidnego przygotowania kondycyjnego, bo bogactwo wątków może przyprawić niektórych czytelników o zawrót głowy. Tym niemniej każdy, kto chciałby poznać uroki interdyscyplinarności, w tym wypadku opartej na połączeniu między innymi przekładoznawstwa, Translator Studies, urbanistyki i literatury porównawczej, powinien zaprzyjaźnić się z tą książką. 


\section{Bibliografia}

Bachmann-Medick, Doris. 2013. The Translational Turn, w: Y. Gambier, L. van Doorslaer (red.), Handbook of Translation Studies, Vol. 4. Amsterdam: John Benjamins, s. 186-193.

- 2016. Cultural Turns, przeł. A. Blauhut, Berlin - Boston: De Gruyter.

Bassnett, Susan. 1998. The translation turn in cultural studies, w: S. Bassnett, A. Lefevere (red.), Constructing Cultures: Essays on Literary Translation, Clevedon: Multilingual Matters, s. 123-140.

- 2012. From Cultural Turn to Translational Turn: A Transnational Journey, w: C. Alvstad, S. Helgesson, D. Watson (red.), Literature, Geography, Translation: Studies in World Writing, Newcastle: Cambridge Scholars Publishing, s. 67-80. Heydel, Magda. 2017. Rób swoje, tłumacz! Przekładoznawstwo jako metoda w humanistyce, „Zagadnienia Rodzajów Literackich” LX(3), s. 11-23.

Simon, Sherry. 2003. Gender in Translation. Cultural Identity and the Politics of Transmission, London - New York: Routledge.

- 2006. Translating Montreal. Episodes in the Life of a Divided City, Montreal - London - Ithaka: McGill-Queen's University Press.

- 2019. Translation Sites: A Field Guide, London - New York: Routledge [e-book].

- 2020. Miasta w przekładzie. Skrzyżowania języka i pamięci, przekł. zbiorowy pod red. M. Heydel , Kraków: Wydawnictwo Uniwersytetu Jagiellońskiego. 